\title{
QUANDO AS PERTURBAÇÕES EM SALA DE AULA ESTÃO ALÉM DOS PROBLEMAS DE COMPORTAMENTO: UMA ANÁLISE LINGÜÍSTICA DAS DIVERGÊNCIAS ENTRE PROFESSOR E ALUNO ${ }^{1}$
}

\author{
Denise Lino de Araújo \\ Universidade Federal da Paraíba - Campus II - \\ Campina Grande
}

\section{INTRODUÇÃO}

Muito se tem dito a respeito do fracasso da escola brasileira, em especial o da escola pública (Soares, 1986; Freire e Shor, 1987; Freitag, 1988). Tem-se apontado para esse problema diversas causas, mas, na minha opinião, uma dessas ainda está por ser estudada de modo mais aprofundado. Estou me referindo especificamente aos choques culturais que cotidianamente estão se reproduzindo nas salas de aulas entre professor e aluno e que revelam o quanto esses sujeitos não se entendem quando interagem com práticas letradas. Isto se deve ao modelo de escola que temos no Brasil, formado tão somente a partir das práticas letradas de um determinado grupo social.

Em função disso, o aluno cuja socialização primária não envolve a escrita de forma direta é um potencial candidato à exclusão, cujo aspecto mais perverso é que ela se dá, via de regra, pelo fato de o aluno não se adaptar à rotina escolar, sendo, por isso, considerado incapaz, defasado e até mesmo insubordinado (o que no discurso escolar é um sinônimo de

Este trabalho retoma parte do $3^{\circ}$ Capitulo da minha dissertaçào de Mestrado, indicada na referenncia bibliográfica deste trabalho. e se constitui também numa versão do trabalho homônimo apresentado no XIX Congresso Internacional da Federação dos Professores de Linguas Vivas, realizado no Recife, em fevereiro de 1997. 
pequeno delinqüente). Assim, o aluno é excluído da escola porque é "diferente culturalmente". Isto quer dizer, em suma, que os seus valores, as suas formas de compreender $e$ interpretar o mundo, as suas práticas culturais de repasse e obtenção de informação, de aprendizagem são diferentes das utilizadas na escola. Nesse caso, o aluno é excluído não porque não aprende, mas porque a escola não sabe ensinar a quem não convive com a escrita.

A respeito dessas questões, a tese que defendo neste trabalho - a da diversidade cultural - não é nova, outros autores já a exploraram como muita propriedade (Heath, 1983, 1986; Hundeide, 1985; Kleiman, 1993, 1995; Signorini, 1994, 1995). A colaboração que apresento é uma análise lingüísticointerpretativa sobre as divergências culturais que se salientam na interação entre alfabetizador e alfabetizandos em atividades escolares, nas aulas de lingua materna, centradas em referências letradas. O principal objetivo deste trabalho é, portanto, o de contribuir para uma discussão mais aprofundada sobre essa questão.

Inicialmente, é importante destacar que os dados utilizados como suporte empírico foram coletados durante uma pesquisa-ação que realizei em 1994, sobre o processo de elaboração do texto escrito, junto a três turmas de alfabetização de jovens e adultos, de uma escola pública da cidade de Campina Grande (Cf. Araújo, 1995). Aqui serão focalizados dois eventos: um em que apenas o professor e dois dos alunos discutem sobre a realização de uma atividade escrita e outro em que toda a turma se envolve.

Focalizando exemplos como esses, os estudos sobre os conflitos interculturais apontam que diferenças de acesso às práticas letradas, especialmente às práticas letradas de prestígio, costumam determinar diferenças no modo de entender, utilizar e explicar ações que envolvem (in)diretamente a escrita (cf. Heath, 1983; Erickson, 1990; Hundeide, 1985; Signorini, 1993; Kleiman, 1995).

Tais diferenças podem vir à tona em qualquer situação de interação/negociação, desde que uma referência escrita esteja em jogo. Na sala de aula de língua materna, essas 
diferenças freqüentemente se apresentam quando professor e alunos não têm na mesma socialização primária o mesmo tipo de envolvimento com a escrita. Normalmente, os freqüentes sinais de perturbação em sala de aula se constituem em indícios de que professor e alunos não se entendem quanto aos usos e valores da escrita. Em termos gerais, essas "perturbações" dão sinais de resistência à imposição da perspectiva do professor na condução da aula, ou são a tentativa de reorientação dessa perspectiva em função dos interesses e dificuldades dos alunos.

\section{ANÁLISE E DISCUSSÃO DOS DADOS}

Nos eventos aqui focalizados, um dos tipos mais comuns de "perturbação" é o fato de o professor e os alunos não atribuírem o mesmo valor para diferentes fontes de informação e, por isso, se desentenderem durante a realização de atividades que envolvem a escrita. Aparentemente, a situação de interação aponta para um entendimento, dentro das normas de interação professor $X$ alunos, visto que esses não se recusam formalmente a realizar as atividades.

Entretanto, a análise desses eventos demonstra que a conversa entre o professor e os alunos antes e/ou durante a realização da atividade revela uma significativa diferença de perspectiva. Na verdade, cada um desses sujeitos parece tentar impor a sua compreensão a respeito do uso dos materiais escritos, conforme demonstra o exemplo ${ }^{2}$ a seguir:

Nos exemplos aqui transcritos segue-se o padrão de transcrição proposto por MARCUSCHI (1986): : alongamento de vogal, II falas simultâneas, | sobreposição de vozes, " subida rápida (corresponde mais ou menos a elevação de voz na interrogação), ' subida leve (corresponde mais ou menos a pausa de vírgula ou do ponto e vírgula), I l sobreposição localizada de falas, (+) pausa, / truncamentos bruscos normalmente produzidos nas tomadas de turno por outro falante, LETRAS MAIÚSCULAS, ênfase ou acento forte, ( ( ) comentários do analista, /.../ indicação de transcrição parcial. De nossa parte acrescentamos: $\mathbb{P}$ para indicar o professor, ÁS para indicar uma fala de vários alunos, Ma, $\mathbf{J P}, \mathbf{A D}, \mathbf{F a}$, entre outros, para indicar os alunos. 


\section{Exemplo 01 - 4/4/94}

Atividade em Curso: Levantamento de hipóteses para o titulo de uma noticia de jornal ("Mulher enciumada tenta assassinar policial militar e depois atira na própria cabeça").

I...I

1. P: ((lê o titulo da noticia para os alunos e depois começa a dialogar com eles em função de que fatos poderiam ter motivado a tentativa de assassinato)) se vocês ouvissem uma chamada no jornal da televisão como essa aqui' o que vocês poderiam pensá que tinha motivado a mulhé a tentá matá'

onti'

2. MA: a' eu vi na patrulha da cidade' dixe que ela morreu

3. P: ainda não saiu no jornal se ela havia morrido'

4. Ma: a' pois já deu na patrulha'

5. JP: ei num escuta a patrulha não"

6. P: não eu nunca tô em casa nesse horário não' bom' mas eu troxe a mesma noticia que acho deu na patrulha e saiu no jornal' vamo compará'

I...I

Esse exemplo.é representativo de uma série de outros. A sua análise demonstra que, embora o professor tenha se utilizado de uma referência letrada de base oral bastante conhecida de toda a turma - o telejornal - como suporte para a discussão de um texto escrito, isto parece ser descabido aos olhos dos alunos, uma vez que eles apontam uma fonte oral (o programa policial radiofônico Patrulha da Cidade) como uma autêntica fonte de informação ( a' eu vi na patrulha da cidade' dixe que ela morreu onti').

Observa-se, nesse trecho da interação, que tanto o aluno que havia iniciado a discussão com o professor se posiciona, reafirmando a veracidade do fato (a' pois já deu na patrulha), como também um outro realça a legitimidade de uma fonte tão familiar para eles, mas desconhecida do professor, conforme demonstra o turno 06 (não eu nunca tô em casa nesse horário não' bom'mas eu troxe a mesma noticia que eu acho que saiu no jornal' vamo compará).

Como se pode observar, nesse caso, a reação dos alunos é desencadeada pelo professor que, mais familiarizado com as fontes escritas, não se dá conta de que os alunos, 
oriundos de grupos sociais com larga tradição oral, não estão familiarizados com as referências letradas e enfrentam dificuldades quando as aulas são compostas exclusivamente por esse tipo de fonte. Ao insistir no texto como principal fonte de interesse na aula de leitura, senão única, o alfabetizador, então, acaba criando situações em que a importância por ele atribuida ao texto informativo parece questionável, quando não despropositada, gerando conflitos quanto ao entendimento do que são as fontes válidas para estudo em sala de aula.

Um outro tipo de "perturbação" também freqüente no corpus, sobretudo no inicio da intervenção, são as tentativas de mudança ou de reorientação do tópico em discussão, através da narração, pelos alfabetizandos, de casos conhecidos ou vividos por eles. Essas intervenções ocorrem em diferentes momentos da aula (antes da apresentação ou correção de atividades, durante a discussão de textos).

No caso da pesquisa-ação aqui focalizada, os relatos são iniciados por um aluno, que de imediato conta com a atenção de vários outros que passam também a contribuir para o desenrolar da estória, transformando a aula numa conversa informal, como no caso do exemplo a seguir, extraido de uma aula de leitura e de produção escrita na turma de Alfabetização.

Exemplo 02 - 26/4/94

Atividade em curso: Leitura oral de receitas de chá escritas pelos alunos

\section{I...I}

1. P: vamo lá quem escreveu a receita pode lê'

2. AD: fessora' a irmã dele ((apontando para um colega sentado ao seu lado)) tá com cólera'

3. P: é mesmo Fa" ((referindo-se ao aluno apontado))

4. FA: é não'

5. As: é é:...: é

6. AD: você mermo disse'

7.P: veja só' a gente viu aqui' que se tivé com cólera' o único remédio é i $\cdots$ pru hospital pra sê tratado ((incomp)) é dificil sê curado'

8. LA: [ou pru cemitério mais próximo] 
9. FA: ela num tá cólera não'

10 P: bom' então' quem fez a atividade" ((os alunos continuavam conversando sobre o tópico iniciado por $A D))(+)(+)$ Fa' isso é verdade que a sua irmã teve cólera"

11. SU: foi é verdade'

12. FA: (quem tava lá pra sabê")

13. SU: (num tava mais sabe)

14. P: FA não tem problema não' ninguém aqui tá brigano porque sua irmã teve cólera'

15. FA: ((barulho)) fica inventano que minha irmã teve cólera tá morreno'

16. P: agora me responda' levaram sua irmã pru hospital ou trataram em casa mesmo"

17. JA: trataram'

18. SO: levaram pró hospital

19. DA: [três dia]

20. P: deixa ele responde' a irmã é dele' ele sabe do assunto ((a impressão que se tem é que muitos alunos sabem do caso e cada um quer contar a sua versão))

21. DA: ela foi pra maternidade' ((risos))

22. P: a' TO ACHANDO QUE VOCÊS QUEREM É FOFOCÁ' VAMO BOTANO UM FIM NESSE CASO E VOLTANO PRA A ATIVIDADE' ((os alunos ficam em silêncio e voltam a acompanhar a atividade que está sendo realizada))

I...l

Nesse caso, mais uma vez, a análise dos dados demonstra que professor e alunos se desentendem quanto à importância que deve ser atribuída à atividade que envolve a escrita. De um lado, está o professor, tentando realizar a atividade de leitura e, do outro, estão os alunos que não atribuem a mesma importância à atividade e preferem iniciar uma conversa, e esta surge no turno 1, quando o alfabetizador está propondo a apresentação das atividades escritas (vamo lá quem escreveu a receita pode lê').

Ao ser interpelado por AD, no turno 2, o alfabetizador é tomado como o seu principal interlocutor (fessora' a irmã dele tá com cólera') o que o leva, inicialmente, a participar da conversa relacionando o caso anunciado com um assunto já estudado em sala de aula (veja só' a gente viu aqui' que se tivé com cólera' o único remédio é $i::$ pru hospital pra sê tratado), 
para só depois tentar voltar à atividade proposta inicialmente (bom' então' quem fez a atividade). Mas os alunos retomam o caso da irmã de FA (foi é verdade), monopolizam o primeiro momento da conversa (vide turnos 2 a 9) e tomam o turno do alfabetizador, que ainda tenta no turno 20 (dexa ele respondê' a irmã é dele' ele sabe do assunto) reassumir o controle da distribuição de turnos. Isso, de fato, só acontece no turno seguinte, depois de contado o desfecho da estória e atingido o efeito desejado (risos). O que é interessante verificar aqui é que, em intervenções desse tipo, a participação dos alunos é muito grande, contribuindo com novas informações, como nos turnos 17 (trataram), 18 (levaram pro hospital), 19 (três dia) e 21 (ela foi pra maternidade), contribuindo com sinais de interesse pelo caso, como nos turnos 5 (é é:.:.: é) e 11 (foi é verdade' ) ou contribuindo com observações sobre o caso focalizado, como no turno 8 (ou pru cemitério mais próximo) e 13 (num tava mais sabe). Aqueles que não se manifestam prestam atenção, mantendo-se em silêncio.

Nesse caso, percebe-se que, apesar do ajuste de perspectiva (Hundeide, 1985) do alfabetizador em sua tentativa de participar da conversa e de reorientá-la para o tópico central da aula, permanecem conflitantes nesse exemplo as duas perspectivas sobre o que pode e o que deve ser comentado durante a aula.

De um lado, a perspectiva acadêmica do professor segundo a qual não deve haver digressões durante a aula, todas as dicussões devem estar relacionadas ao tópico central da aula e, mesmo quando um outro assunto surge, faz-se necessário relacioná-lo a alguma das aulas já ministradas. É isso o que ele faz quando intervém várias vezes, tentando retomar o controle da situação para estabelecer relação entre o caso narrado pelos alunos e os assuntos vistos em aula.

Do outro lado, a perspectiva de tradição oral dos alunos segundo a qual informações advindas da escrita comumente não são as mais relevantes, sobretudo quando já se tem um domínio oral do texto, como no caso das receitas. Ademais, parece que, para os alunos, o raciocínio de interpretação de uma aula assemelha-se ao de uma conversa informal, ou seja, se várias pessoas estão em interação face-a-face qualquer 
índice lingüístico pode ser motivo para uma mudança de tópico, como se se dissesse: "ah! por falar nisso..." No caso aqui analisado, o raciocinio dos alunos provavelmente equivale a: " por falar em leitura de receitas de chá que tem a ver com doenças, você soube que a irmã de Fá esteve 'doente'?"

De acordo com Kleiman (1993:425), que também registrou este tipo de evento em aulas de alfabetização de adultos numa cidade do interior de São Paulo, essas intervenções podem também ser decorrentes da interpretação que os alunos fazem de determinadas atividades propostas durante a aula. Num dos casos analisados por essa autora, os alunos interpretaram um pedido de classificação de eventos de discriminação racial, a partir da leitura de uma noticia sobre discriminação, como um pedido de relato de experiências pessoais de discriminação.

Situações como essas não raro são reproduzidas em sala de aula, sendo muito comumente enfrentadas pelo professor como sinônimo de insubordinação dos alunos. Nesses casos, portanto, o que de fato ocorre são as manifestações de perspectivas diferentes para interpretar um mesmo evento que envolve a escrita.

\section{CONSIDERAÇÕES FINAIS}

Os exemplos aqui discutidos trazem, em sentido estrito, uma contribuição para a discussão sobre a questão dos conflitos entre professor e aluno, que geram "perturbações" em sala de aula. E em sentido amplo, esses mesmos exemplos contribuem para uma reflexão sobre o amplo quadro de fracasso que caracteriza a escola brasileira.

De acordo com os dados, é possivel perceber que essas "perturbações" parecem ter uma gênese comum: diferenças de perspectivas na interpretação de eventos que envolvem a escrita. Tais diferenças, que estão relacionadas com diferenças de acesso ao modelo de letramento prestigiado pela escola, não são completamente neutralizadas pela adoção de uma linguagem comum ou pelo respeito às normas de interação em sala de aula. Em termos gerais, essas 
perturbações tanto dão sinal de resistência à imposição do professor na condução da aula, quanto se constituem na tentativa de reorientação dessa perspectiva em função das dificuldades e interesses dos alunos

"Perturbações" do tipo focalizado neste trabalho me parecem ser de grande importância para a compreensão da dinâmica da sala de aula, porque reclamam uma investigação mais aprofundada que identifique as suas raízes e possam ajudar o professor a continuamente avaliar e (re)planejar a sua prática de ensino, procurando, através do ajuste de perspectiva, torná-la mais simétrica.

Nesse sentido, convém (re)examinar o fracasso da escola brasileira, em especial o fracasso do ensino de língua materna, corriqueiramente atribuido apenas a problemas de comportamento dos alunos. Portanto, conforme aqui demonstrado, nem sempre as perturbações em sala de aula têm origem na indisciplina do comportamento dos alunos.

\section{REFERÊNCIAS BIBLIOGRÁFICAS}

ARAÚJO, D. L. A construção da intertextualidade na produção textual de alfabetizandos adolescentes e adultos. Campinas, 1995. Dissertação de Mestrado, Unicamp.

ERICKSON, F. Qualitative methods. In: Research teaching and learning. New York: Machillean Publishing Company, 1990. v.2.

FREIRE, P.; SHOR, I. Medo e ousadia: cotidiano do professor. Rio de Janeiro: Paz e Terra, 1987.

FREITAG, B. Diário de uma alfabetizadora. Campinas: Papirus, 1988.

HEATH, S. B. Ways with words: language, life and works in communities and classroom. Cambridge: Cambridge University Press, 1983. 
HEATH, S. B. The funcions and uses of life. In: CASTEL et al. Literacy, society and schooling. Cambrigde: Cambridge University Press, 1986. p. 15-26.

HUNDEIDE, K. The tacit background of children's judgments. In: WERTSCH, J. V. Culture, communucation and cognition: vygotskian perspectives. Cambridge: Cambridge University Press, 1985. p. 306-321.

KLEIMAN. A. Interação e produção de textos: elementos para uma análise interpretativa crítica do discurso do professor. D.E.L.T.A., v. 9, n. especial, p. 417-435, 1993b.

KLEIMAN. A. Estudos sobre o letramento: uma nova perspectiva sobre a prática social da escrita. In: Os significados do letramento: uma nova perspectiva sobre a prática social da escrita. Campinas: Mercado de Letras, 1995. p. 15-61.

MARCUSCHI, L. A. Análise da conversação. São Paulo: Ática, 1986.

MULHER enciumada tenta assassinar policial e depois atira na própria cabeça. Jornal da Paraiba, Campina Grande, cad. 2, p 4, 15 mar. 1994.

SIGNORINI, I. Letramento e discurso explicativo. Letras \& letras. v. 8, n. 2, p. 21-49, dez. 1993.

SIGNORINI, I. Esclarecer o ignorante: a concepção escolarizada do acesso ao mundo da escrita. The Especialist. São Paulo, v. 15, n. 1/2, p. 163-171, 1994.

SIGNORINI, I. Letramento e (in) flexibilidade comunicativa. In: KLEIMAN, A. B. (Org.). Os significados do letramento: uma nova perspectiva sobre a prática social da escrita. Campinas: Mercado de Letras, 1995. p. 161-199.

SOARES, M. B. Linguagem e escola: uma perspectiva social. São Paulo: Ática, 1986. 